\title{
A NOVA ORDEM DA INFORMAÇÃO E O ESTA- DO DO ACRE
}

LUIS SATIE

Universidade Federal de Paraíba, João Pessoa, Paraíba, Brasil

e-mail: (uis.satie@alumni-ehess.fr

CIRO JONATAS DE SOUZA OLIVEIRA Universidade Federal de Paraíba, João Pessoa, Paraíba, Brasil

e -mail: cirojonatas@gmail.com 


\section{A NOVA ORDEM DA INFORMAÇÃO E O ESTADO DO ACRE}

Resumo: Com o advento da Lei $\mathrm{n}^{\circ} 12.527$, de 18 de novembro de 2011, o direito constitucional à informação ganhou procedimentos que vinculam toda a esfera pública. Essa pesquisa mostra, por meio de cuidadoso estudo exploratório de portais eletrônicos disponíveis, que o Estado do Acre não está ainda em consonância com essa nova ordem informativa. Palavras chave: Informação; Lei n ${ }^{\circ}$ 12.527/2011; Acre

\section{EL NUEVO ORDEN DE LA INFORMACIÓN Y EL ESTADO DE ACRE}

Resumen: Con la promulgación de la Ley ${ }^{\circ}$ 12.527, de 18 de noviembre de 2011, el derecho constitucional a la información ha obtenido los procedimientos que son vinculantes para todos en la esfera pública. Esta investigación muestra, a través del estudio exploratorio de portales electrónicos disponibles que el Estado de Acre aún no está en consonancia con el nuevo orden de la información. Palabras clave: Information; Ley $n^{\circ}$ 12.527/11; Acre

\section{THE NEW ORDER OF INFORMATION AND THE STATE OF ACRE}

Abstract:Withthe enactment of Lawn ${ }^{\circ} 12,527$, of November18, 2011, the constitutionalrighttoinformationgained proceduresthatbindtheentirepublicsphere. Thisresearchshows, throughcarefulexploratorystudyofelectronicportals available that the State of Acre is not yet in line with the new information order. Keywords: Information; Law n 12,527 / 2011; Acre 


\section{INTRODUÇÃO}

Uma democracia não sobrevive sem procedimentos claros à disposição do cidadão. Esses procedimentos devem ter eficácia geral, após esgotar-se todo um ciclo de discussões no Poder Legislativo. Esse protocolo jurídico está sendo seguido rigorosamente na seara do direito à informação em nosso país? O objetivo dessa pesquisa é aferir se os procedimentos definidos nessa esfera dos direitos fundamentais estão sendo seguidos pelo Estado do Acre. $O$ estudo teve como foco a investigação dos portais eletrônicos disponíveis, por meio da navegação e acesso em suas plataformas, no período de 04 a 08/03/2014. O estudo dos sítios foi orientado por critérios legais, que alimentaram uma planilha de dados, a fim de possibilitar o cálculo do percentual de atendimento às exigências da nova ordem informativa. Com base nessa pesquisa, tem-se que a esfera pública do Estado do Acre, com base no período examinado, está em débito para com os parâmetros de transparência esperados por nossa ordem jurídico-política e constitucional.

\section{O DIREITO À INFORMAÇÃO}

Com a promulgação da Constituição vigente anunciou-se uma nova maneira de tratamento da informação em nosso país. A sociedade brasileira decidiu no art. $5^{\circ}$, XXXIII que "todos têm direito a receber dos órgãos públicos informações de seu interesse particular, ou de interesse coletivo ou geral, que serão prestadas no prazo da lei, sob pena de responsabilidade, ressalvadas aquelas cujo sigilo seja imprescindível à segurança da sociedade e do Estado". Decidiu também que esse direito à informação não é absoluto, ao estatuir, no inciso $X$ do mesmo artigo que "são invioláveis a intimidade, a vida privada, a honra e a imagem das pessoas, assegurado o direito a indenização pelo dano material ou moral decorrente de sua violação".

Lembremos que o art. $5^{\circ}$ de nossa Constituição condensa os direitos e garantias fundamentais, mais especificamente os direitos e deveres individuais e coletivos, que precedem a organização do Estado Administrativo. Isso quer dizer que o povo brasileiro decidiu que direito à informação é ao mesmo tempo anterior e superior à administração das coisas e pessoas. Ou seja, o direito à informação não é sequer o alicerce do edifício institucional: ele é a terraplenagem que permite que esse alicerce não seja construído sobre solo inseguro, perigoso, insalubre e insustentável. 
Por essa razão o art. $37, \S 3^{\circ}$, II de nossa Lei Maior, quando se refere ao acesso dos usuários a registros administrativos e a informações sobre atos de governo, é obrigado a fazer remissão ao disposto no art. $5^{\circ}$, X e XXXIII, reproduzidos acima. Remissão esta que soa implícita no texto do art. 216, § $2^{\circ}$ : "Cabem à administração pública, na forma da lei, a gestão da documentação governamental e as providências para franquear sua consulta a quantos dela necessitem". Em outras palavras, cabe ao administrador público o dever de informar ao povo - único detentor da soberania - acerca de suas atividades, melhor, acerca de sua governança, de seus planos, metas, métodos e resultados. Cabe-lhe, também, informar ao povo soberano sobre seus erros, falhas, problemas e impossibilidades. Isso porque numa democracia o povo não é apenas o autor da terraplenagem, que permite a construção do edifício do Estado sobre bases confiáveis. O povo é também o arquiteto de toda a estrutura administrativa e, como tal, tem todo o interesse de saber se essa estrutura não está se corrompendo ou sendo mal posta no tempo e no espaço da soberania, da cidadania, da dignidade da pessoa humana, dos valores sociais do trabalho e da livre iniciativa e do pluralismo político, ou seja, no tempo e espaço do Estado Democrático de Direito.

Esse dever de gestão permanente da qualidade de nossa democracia é tão enfático que é dever do servidor público federal, segundo o inciso VI do art. 116 da Lei n ${ }^{\circ}$ 8.112, de 11 de dezembro de 1990: "VI - levar as irregularidades de que tiver ciência em razão do cargo ao conhecimento da autoridade superior ou, quando houver suspeita de envolvimento desta, ao conhecimento de outra autoridade competente para apuração". Ora, isso implica que antes de render seus serviços ao gestor público o servidor deve obediência ao soberano. Isso porque por trás de cada servidor público reside um cidadão, que lhe é anterior e superior. E uma vez que esse cidadão participa da soberania ele é imune no exercício da cidadania, imunidade essa que não alcança o servidor público. Assim, o servidor está para o Estado administrativo assim como o cidadão está para o Estado constitucional. Se aquele deve obediência hierárquica aos seus chefes, este é anterior e superior à trama organizacional de servidores e chefes, pois participa da soberania. Não é por acaso que a cidadania está posta como princípio fundamental de nosso Estado Democrático de Direito, justamente ao lado da soberania, no art. $1^{\circ}$ de nossa Constituição da República. Eis porque o servidor, diante de um ato de corrupção ou atentatório aos valores fundamentais de nossa democracia, deve assumir seu dever de cidadania, com todo vigor e coragem, sob a 
proteção de nossa ordem jurídica, que no art. 126-A da Lei no 8.112, de 1990 assegura: "Nenhum servidor poderá ser responsabilizado civil, penal ou administrativamente por dar ciência à autoridade superior ou, quando houver suspeita de envolvimento desta, a outra autoridade competente para apuração de informação concernente à prática de crimes ou improbidade de que tenha conhecimento, ainda que em decorrência do exercício de cargo, emprego ou função pública."

\subsection{A Lei de Acesso à Informação}

A Lei de Acesso à Informação - LAI (Lei n 12.527 , de 18 de novembro de 2011) vem apenas dar sede infraconstitucional a esses dispositivos no meIhor estilo, trazendo procedimentos públicos de acesso ao cidadão, como enunciado em seu art. $1^{\circ}$. Além disso, todos os órgãos públicos - abrangendo os três poderes e o Ministério Público - de todas as entidades federativas são obrigados a dar um tratamento democrático às informações que Ihes são atinentes, como estatuído no parágrafo único daquele dispositivo. Trata-se, portanto, de uma abrangência universal da lei, dando-lhe o caráter de uma verdadeira ação popular de controle da informação pública e de reafirmação do resguardo da vida privada, garantido pelo art. $5^{\circ}, \mathrm{X}$ da CF. A Lei de Acesso à Informação entrou em vigor 180 dias após a sua publicação, ou seja, seus dispositivos são exigíveis desde 16 de maio de 2013. Posto isso, todos os órgãos públicos de todos os poderes já deveriam estar alinhados a essas exigências legais, por meio da criação de sites na internet, comumente chamados de "portais da transparência", para a efetiva disponibilização de informações públicas aos cidadãos. Não obstante, a esfera privada não está absolutamente imunizada pela LAI. Toda entidade privada, sem fins lucrativos, que receba recursos públicos é obrigada a informar à sociedade sobre sua origem e destinação e esta informação não poderá fazer as vezes de uma prestação de contas, que continua vinculada ao regime fiscalizatório da seção IX do Título IV (Da organização dos poderes) c/c art. 31 da CF.

É notório que a nova Lei traz um novo tipo de prestação de contas para o nosso regime constitucional-administrativo: a prestação de contas (em sentido lato) da informação que o espaço público estatal ou não estatal se utiliza para a definição de suas políticas. Se considerarmos que nenhuma prestação de contas se sustenta sem a qualidade e ubiquidade de seu teor, ou seja, sem sua capacidade de ser comunicada à sociedade com simplicida- 
de e eficiência, podemos concluir que a LAl traz uma mudança de paradigma na relação Estado-Sociedade. Precisamente, ao provocar que a informação circule e entre no mundo da circulação de ideias, no mundo da vida social, essa lei nos convida ao exercício da razão comunicativa, pois numa democracia a informação pública não pode ser insulada nem sonegada. Nesse sentido, o gestor deve estar preparado para o uso compartilhado da razão. É o que está implícito no art. $3^{\circ}$ e art. $4^{\circ}$, cujos incisos remetem a informação para o mercado da razão, sem o que o cidadão e sociedade civil não podem avançar em sua formação do juízo público. Os incisos I - V do art. $3^{\circ}$ e I - IX do art. $4^{\circ}$, portanto, são propulsores da circulação de conteúdos públicos, transformando o dado, o registro e o cadastro em insumo comunicativo.

Essa nova figura legislativa conjuga, portanto, a ideia de universalidade com a de reciprocidade. No entanto, a nova lei traz mais um avanço, sem o que nossa democracia formal não poderá se converter em virtudes públicas efetivas praticadas pelos agentes de Estado e pelos cidadãos: trata-se da procedimentalização de suas promessas normativas. Com efeito, a LAI alberga em seus dispositivos o princípio da transparência ativa, ao estabelecer no artigo $8^{\circ}$ que as informações de interesse coletivo ou geral deverão ser divulgadas de ofício pelos órgãos públicos, espontânea e proativamente, independentemente de solicitações. Inclusive, há um rol mínimo de informações que os órgãos e entidades públicas devem obrigatoriamente divulgar na internet, excetuando-se desse compromisso legal os municípios com população de até 10.000 (dez mil) habitantes.

Por fim, além de seu caráter universal, recíproco e procedimental a Lei de Acesso à Informação é também uma lei processual, que resguarda o contraditório ( $\operatorname{art.} 32, \delta 1^{\circ}$ ) em cada passo das demandas que lhe são propostas. Por essa razão, o legislador incumbiu à Controladoria-Geral da União, por meio do caput do art. 16 da LAI, o papel de segunda instância recursal no caso de indeferimento de acesso a informações (a primeira é a autoridade hierarquicamente superior à que exarou a decisão impugnada). Posteriormente, como previsto no art. $16, \S 3^{\circ}$ do mesmo estatuto, também há possibilidade de interposição de recurso à Comissão Mista de Reavaliação de Informações, que funciona na Casa Civil da Presidência da República.

A força normativa da LAI vem, pois, complementar o âmbito normativo da Lei Complementar $n^{\circ} 101$, de 4 de maio de 2000, conhecida como Lei de Responsabilidade Fiscal (LRF), alterada pela Lei Complementar $n^{\circ} 131$, de 27 de maio de 2009. Aqui a informação já ganhava a natureza de uma pres- 
tação de contas no sentido estrito do termo, contemplando mecanismos para transparência da gestão fiscal, que consistem principalmente na obrigatoriedade de disponibilização, em meio eletrônico e em tempo real, de informações pormenorizadas sobre a execução orçamentária e financeira de suas receitas e despesas. Criada para alterar a Lei de Responsabilidade Fiscal (Lei Complementar $n^{\circ} 101$, de 4 de maio de 2000), no tocante à transparência da gestão, a $L C n^{\circ}$ 131/2009 não excluiu os Municípios com população de até 10.000 (dez mil) habitantes da obrigatoriedade de transparência da gestão fiscal. Com efeito, ao definir prazos diferentes para o cumprimento de seus dispositivos, a LRF estabeleceu, no Inciso III do art. 73-B, para os municípios com até cinquenta mil habitantes o prazo máximo de 4 (quatro) anos para o cumprimento de suas determinações, prazo esse que se esgotou em 28 de maio de 2013. A não disponibilização das informações exigidas de acordo com o modelo previsto na legislação pode implicar na aplicação de diversas sanções. Entre elas, os entes da Federação podem ser impossibilitados de receber transferências voluntárias de recursos da União, como estatuído no art. 23, §3으. Inciso I, c/c art. 48-A da LRF. Além disso, o titular do Poder Executivo, seja da esfera federal ou municipal, estará sujeito a responder por crime de responsabilidade, como prescrito no art. 10, Itens 4 e 12 da Lei $n^{\circ}$ 1.079, de 10 de abril de 1950 e no art. $1^{\circ}$, Incisos VI e VII do Decreto-Lei $n^{\circ} 201$, de 27 de fevereiro de 1967, respectivamente.

\subsection{Transparência ativa}

Foi realizado estudo da adequabilidade dos portais de transparência dos órgãos e entes do Poder Executivo, Poder Legislativo (neste abrangido também o Tribunal de Contas), Poder Judiciário e Ministério Público localizados no Estado do Acre.

Para isso, foram consideradas as disposições da Lei de Acesso à Informação - LAI (Lei no 12.527, de 18 de novembro de 2011), Lei Complementar $n^{\circ}{ }^{131}$, de 27 de maio de 2009, Lei de Responsabilidade Fiscal (Lei Complementar $\mathrm{n}^{\circ}$ 101, de 4 de maio de 2000), Decreto $n^{\circ} 7.185$, de 27 de maio de 2010 e Lei $n^{\circ}$ 9.755, de 16 de dezembro de 1998.

As disposições da LRF contemplam, principalmente, um conteúdo mínimo de informações, com um nível de detalhamento obrigatório referente à execução orçamentária e financeira das receitas e despesas da Administração Pública. Por sua vez, além de um conteúdo mínimo, a LAl estabelece 
no $\S 3^{\circ}$ do artigo $8^{\circ}$ que os sites deverão obedecer aos seguintes requisitos obrigatórios para a disponibilização das informações:

I - conter ferramenta de pesquisa de conteúdo que permita o acesso à informação de forma objetiva, transparente, clara e em linguagem de fácil compreensão;

II - possibilitar a gravação de relatórios em diversos formatos eletrônicos, inclusive abertos e não proprietários, tais como planilhas e textos, de modo a facilitar a análise das informações;

III - possibilitar o acesso automatizado por sistemas externos em formatos abertos, estruturados e legíveis por máquina;

IV - divulgar em detalhes os formatos utilizados para estruturação da informação;

$\mathrm{V}$ - garantir a autenticidade e a integridade das informações disponíveis para acesso;

VI - manter atualizadas as informações disponíveis para acesso;

VII - indicar local e instruções que permitam ao interessado comunicar-se, por via eletrônica ou telefônica, com o órgão ou entidade detentora do sítio; e

VIII - adotar as medidas necessárias para garantir a acessibilidade de conteúdo para pessoas com deficiência, nos termos do art. 17 da Lei no 10.098, de 19 de dezembro de 2000, e do art. $9^{\circ}$ da Convenção sobre os Direitos das Pessoas com Deficiência, aprovada pelo Decreto Legislativo $n^{\circ} 186$, de 9 de julho de 2008.

Esses requisitos visam garantir a ampla transparência e alinham-se ao conceito de dados abertos.

\subsection{Dados abertos}

Segundo a definição da Open Knowledge Foundation, organização sem fins lucrativos fundada em maio de 2004, com o fim de promover o conhecimento livre, dados são abertos quando qualquer pessoa pode livremente usá-los, reutilizá-los e redistribuí-los, estando sujeito, no máximo, à exigência de creditar a sua autoria e compartilhar a mesma licença (http://dados. gov.br/dados-abertos/).

Para tanto, os dados devem ser completos, primários, atuais, acessíveis, 
processáveis por máquinas, de acesso não discriminatório, de formatos não proprietários e livres de licença. Completos, porque todos os dados públicos devem ser disponibilizados. Dados são informações eletronicamente gravadas, incluindo, mas não se limitando a documentos, bancos de dados, transcrições e gravações audiovisuais. Dados públicos são dados que não estão sujeitos a limitações válidas de privacidade, segurança ou controle de acesso, reguladas por estatutos. Primários, pois os dados devem ser publicados na forma coletada na fonte, com a mais fina granularidade possível, e não de forma agregada ou transformada. Atuais, uma vez que os dados devem ser disponibilizados o quão rapidamente seja necessário para preservar o seu valor. Acessíveis, na medida em que os dados devem ser disponibilizados para o público mais amplo possível e para os propósitos mais variados possíveis. Processáveis por máquina, tendo em vista que os dados devem ser razoavelmente estruturados para possibilitar o seu processamento automatizado. Os arquivos devem ser publicados de forma que sua reutilização não seja limitada, como acontece no caso dos arquivos de imagens: ".PDF”, “.JPG”, “.TIFF”, “.BMP”. De acesso não discriminatório, visto que os dados devem estar disponíveis a todos, sem necessidade de identificação ou registro. De formatos não proprietários, porquanto os dados devem estar disponíveis em um formato sobre o qual nenhum ente tenha controle exclusivo. Arquivos em formato não proprietário são aqueles que podem ser abertos e editados em software livre. Um documento de texto em formato não proprietário, por exemplo, tem uma extensão “.ODF”. Já um arquivo com tabelas, a extensão “.ODS” ou “.CSV”. É importante destacar, no entanto, que essa recomendação não impede que os arquivos sejam publicados, de forma complementar, em formatos proprietários de uso corrente, como os da Microsoft (".DOC" ou “.RTF" para arquivos de texto e ".XLS" para tabelas). Livres de licenças, posto que os dados não devem estar sujeitos a regulações de direitos autorais, marcas, patentes ou segredo industrial. Restrições razoáveis de privacidade, segurança e controle de acesso podem ser permitidas na forma regulada por estatutos.

\subsection{Princípio da ampla transparência}

A Lei de Acesso à Informação foi criada em 2011 com o objetivo de efetivar o direito fundamental de acesso à informação. Para tanto, prima pela indução ao desenvolvimento da cultura de transparência na administração 
pública e pelo desenvolvimento do controle social do Estado Administrativo. O conceito de dados abertos foi inserido nesse contexto, indo ao encontro do pleno exercício do direito de acesso à informação.

Por sua vez, a Lei Complementar n 131, de 27 de maio de 2009 foi criada em um momento anterior, no qual era premente a necessidade de aumento da transparência, controle e fiscalização da gestão fiscal. Esse normativo, assim como a LRF, não aborda, entretanto, o conceito recente de dados abertos, nem dispõe sobre a forma de disponibilização das informações sobre a execução orçamentária e financeira das receitas e despesas.

Todavia, essa lacuna normativa não pode servir de válvula de escape para gestores que não queiram concretizar o direito de acesso à informação. Isso porque essas leis devem ser interpretadas de modo sistêmico e sistemático para otimizar a nova ordem informativa, trazida pela Constituição vigente. $O$ conjunto de normas e princípios que regem o direito de acesso à informação e as práticas de transparência e controle social obrigam que as informações exigidas pela LRF sejam publicadas em consonância com as diretrizes da LAl, inclusive no tocante ao conceito de dados abertos, permitindo que qualquer cidadão possa fazer o download de quaisquer bancos de dados.

Nesse sentido, o Decreto $n^{\circ} 7.185$, de 27 de maio de 2010, que regula a LRF no tocante à transparência da gestão fiscal de todos os entes da Federação, exige que o sistema integrado de administração financeira e controle utilizado no âmbito de cada ente da Federação permita o armazenamento, a importação e a exportação de dados, bem como a integração com meio eletrônico que possibilite amplo acesso público, por meio da aplicação de soluções tecnológicas que visem simplificar processos e procedimentos de atendimento ao cidadão.

Ademais, o rol de conteúdo mínimo da LAl, no artigo $8^{\circ}$, §1 $1^{\circ}$, inciso III, determina a divulgação proativa dos "registros das despesas". Para alinhar-se aos princípios da máxima transparência e amplo acesso à informação, essa plataforma deve abranger informações pormenorizadas, contemplando, no mínimo, o conteúdo exigido pela LRF e pelo Decreto $n^{\circ} 7.185$, de 27 de maio de 2010.

Seguindo essa linha, o Decreto $n^{\circ} 7.724$, de 16 de maio de 2012, que regulamentou a LAI no âmbito do Poder Executivo Federal, substituiu a expressão "registros das despesas" (contida no art. $8^{\circ}, \S 1^{\circ}$, inciso III da LAI) pela expressão "execução orçamentária e financeira detalhada" (art. $7^{\circ}$, § $3^{\circ}$, inciso IV). 


\section{A NOVA ORDEM INFORMATIVA E O ESTADO DO ACRE}

Nessa pesquisa foram considerados 93 itens, que incluem a maioria das variáveis de transparência exigidas pela LAI. A Análise efetuada considerou que quaisquer dados disponibilizados nos portais de transparência devem oferecer a possibilidade de download das bases de dados.

Cabe destacar que a presente investigação contemplou apenas o conteúdo mínimo exigível pela legislação correlata. Vale lembrar que o artigo $8^{\circ}$ da LAl, que trata da transparência ativa, estabelece que os órgãos e entidades públicas devem promover, independentemente de requerimentos, a divulgação em local de fácil acesso, no âmbito de suas competências, de informações de interesse coletivo ou geral por eles produzidas ou custodiadas.

Sem esgotar o assunto, a própria LAl estabeleceu um rol mínimo de informações de interesse coletivo. Desse modo, ao regulamentar a LAI os entes federativos podem incluir outras informações no rol de divulgação obrigatório. Nesse sentido, o Poder Executivo Federal considerou como de interesse coletivo a divulgação de "remuneração e subsídio recebidos por ocupante de cargo, posto, graduação, função e emprego público, incluindo auxílios, ajudas de custo, jetons e quaisquer outras vantagens pecuniárias, bem como proventos de aposentadoria e pensões daqueles que estiverem na ativa, de maneira individualizada" (Decreto $n^{\circ} 7.724$, de 16 de maio de 2012).

Posto isso, as entidades que detenham ou produzam outras informações devem divulgá-las de maneira ativa, quando forem de interesse coletivo ou geral. Um exemplo são os próprios dados de remuneração e subsídio, dados de verbas de gabinete, dados de celulares institucionais, dentre outros. Outro exemplo de grande importância são os dados administrados pelo Tribunal de Contas do Estado, referentes à prestação de contas da execução das despesas dos municípios e câmaras legislativas. Atualmente, o TCE/AC efetua a coleta de dados sobre a execução orçamentária e financeira dos órgãos e entidade por meio Sistema de Acompanhamento da Gestão de Recursos da Sociedade (SAGRES), mas não foram identificados meios de a sociedade acessar esses dados de forma remota, ou seja, sem precisar ir pessoalmente à referida Corte.

\subsection{Padrão de análise}

Para subsidiar a análise dos diversos portais analisados, foi desenvolvido 
um roteiro padrão para análise, dividido em três blocos, a saber: I. Características do sítio eletrônico da seção de acesso à informação; II. Informações mínimas da seção de acesso à informação nos sítios eletrônicos e III. Conteúdo mínimo exigido pela Lei Complementar n 131/2009 e os normativos relacionados a ela. O roteiro aplicado consta nos Quadros 1, 2 e 3:

\begin{tabular}{|l|l|}
\multicolumn{2}{|c|}{ A nova ordem da informação e o Estado do Acre } \\
\hline \multicolumn{1}{|c|}{ Item } & \multicolumn{1}{|c|}{ Informação } \\
\hline 1 & Características do sítio eletrônico da Seção de Acesso à Informação. \\
\hline 1.1 & $\begin{array}{l}\text { O domínio deve seguir o padrão "município.uf.gov.br", segundo a Resolução CGI.br/ } \\
\text { RES/2008/008/P. }\end{array}$ \\
\hline 1.2 & Ferramenta de busca \\
\hline 1.3 & Seção "Fale Conosco" \\
\hline 1.4 & Seção "Perguntas mais frequentes" \\
\hline 1.5 & Acesso livre \\
\hline 1.6 & Possibilidade de acesso por outros sistemas (Possibilidade de download dos dados) \\
\hline 1.7 & Acessibilidade \\
\hline 1.8 & Autenticidade e integridade e atualização da informação \\
\hline 1.9 & Possibilidade de gravação de relatório \\
\hline 1.10 & Divulgação dos detalhes dos formatos utilizados para a estruturação das informações \\
\hline
\end{tabular}

Quadro 1 - Características da Seção de Acesso à Informação

Fonte: Legislação federal correlata

\begin{tabular}{|l|l|}
\hline \multicolumn{1}{|c|}{ Item } & \multicolumn{1}{c|}{ Informação } \\
\hline $\mathbf{2}$ & Informações mínimas da Seção de Acesso à Informação nos sítios eletrônicos. \\
\hline 2.1 & Dados Institucionais \\
\hline 2.1 .1 & Estrutura organizacional (organograma) \\
\hline 2.1 .1 & Competências \\
\hline 2.1 .2 & $\begin{array}{l}\text { Base jurídica da estrutura organizacional e das competências do órgãos/entidade, inclusive } \\
\text { regimentos internos, quando existirem }\end{array}$ \\
\hline 2.1 .3 & Lista dos principais cargos e seus respectivos ocupantes (denominado "Quem é quem") \\
\hline 2.1 .4 & Telefones e endereços de contato dos ocupantes dos principais cargos; agenda de autoridades \\
\hline 2.1 .5 & Horários de atendimento do órgãos/entidade \\
\hline 2.2 & Convênios \\
\hline 2.2 .1 & órgão superior \\
\hline 2.2 .2 & órgão subordinado ou entidade vinculada \\
\hline 2.2 .3 & unidade gestora \\
\hline 2.2 .4 & nome do conveniado \\
\hline 2.2 .5 & número do convênio \\
\hline 2.2 .6 & número do processo \\
\hline 2.2 .7 & Objeto \\
\hline 2.2 .8 & valor do repasse \\
\hline 2.2 .9 & valor da contrapartida do conveniado \\
\hline
\end{tabular}




\begin{tabular}{|c|c|}
\hline Item & Informação \\
\hline 2 & Tnformações mínimas da Seção de Acesso à Informação nos sítios eletrônicos. \\
\hline 2.2 .10 & valor total dos recursos \\
\hline 2.2 .11 & período de vigência \\
\hline 2.3 & Despesas \\
\hline 2.3 .1 & Quadro de Detalhamento de Programas, por unidade orçamentária do órgão/entidade, contendo: \\
\hline 2.3.1.1 & código e especificação dos programas orçamentários \\
\hline 2.3 .1 .2 & $\begin{array}{l}\text { orçamento atualizado, levando em consideração os recursos consignados por programa na Lei } \\
\text { Orçamentária Anual e em seus créditos adicionais }\end{array}$ \\
\hline 2.3 .1 .3 & $\begin{array}{l}\text { valor liquidado no ano considerado, para exercícios encerrados, e valor liquidado até o mês } \\
\text { considerado, para o exercício corrente }\end{array}$ \\
\hline 2.3 .1 .4 & $\begin{array}{l}\text { valor pago no ano considerado, para exercícios encerrados, e valor pago até o mês considerado, } \\
\text { para o exercício corrente }\end{array}$ \\
\hline 2.3 .1 .5 & percentual dos recursos liquidados comparados aos autorizados \\
\hline 2.3 .1 .6 & percentual dos recursos pagos comparados aos autorizados \\
\hline 2.3 .2 & Quadro de Execução de Despesas, por unidade orçamentária dos órgãos e entidades, contendo: \\
\hline 2.3.2.1 & descrição da natureza das despesas \\
\hline 2.3 .2 .2 & $\begin{array}{l}\text { valor liquidado no ano considerado, para exercícios encerrados e valor liquidado até o mês } \\
\text { considerado, para o exercício corrente }\end{array}$ \\
\hline 2.3 .2 .3 & $\begin{array}{l}\text { valor pago no ano considerado, para exercícios encerrados e valor pago até o mês considerado, } \\
\text { para o exercício corrente }\end{array}$ \\
\hline 2.4 & Licitações e Contratos \\
\hline 2.4 .1 & Informações referentes às licitações: \\
\hline 2.4.1.1 & órgão superior \\
\hline 2.4.1.2 & órgão subordinado ou entidade vinculada \\
\hline 2.4 .1 .3 & número da licitação \\
\hline 2.4.1.4 & número do processo \\
\hline 2.4 .1 .5 & modalidade da licitação \\
\hline 2.4 .1 .6 & Objeto \\
\hline 2.4.1.7 & número de itens \\
\hline 2.4 .1 .8 & data e hora da abertura \\
\hline 2.4 .1 .9 & local da abertura \\
\hline 2.4 .1 .10 & cidade da abertura \\
\hline 2.4 .1 .11 & Unidade da Federação da abertura \\
\hline 2.4 .1 .12 & situação da licitação (aberta ou homologada) \\
\hline 2.4 .1 .13 & contato no órgão ou entidade responsável \\
\hline 2.4 .1 .14 & $\begin{array}{l}\text { atalho para solicitação, por meio de correio eletrônico, da íntegra de editais, atas, anexos, } \\
\text { projetos básicos e informações adicionais, diretamente à área responsável do órgão ou entidade }\end{array}$ \\
\hline 2.4 .2 & Relativas aos contratos firmados e notas de empenho expedidas: \\
\hline 2.4.2.1 & órgão superior \\
\hline 2.4 .2 .2 & órgão subordinado ou entidade vinculada \\
\hline 2.4 .2 .3 & número do contrato \\
\hline 2.4 .2 .4 & data de publicação no Diário Oficial do Estado/Município \\
\hline 2.4 .2 .5 & número do processo \\
\hline
\end{tabular}




\section{A NOVA ORDEM DA INFORMAÇÃO E O ESTADO DO ACRE}

\begin{tabular}{|c|c|}
\hline Item & Informação \\
\hline 2 & Tnformações mínimas da Seção de Acesso à Informação nos sítios eletrônicos. \\
\hline 2.4 .2 .6 & modalidade da licitação \\
\hline 2.4 .2 .7 & nome do contratado \\
\hline 2.4 .2 .8 & $\begin{array}{l}\text { número de inscrição do contratado no Cadastro Nacional de Pessoas Jurídicas (CNPJ) ou no } \\
\text { Cadastro de Pessoas Físicas (CPF) }\end{array}$ \\
\hline 2.4.2.9 & Objeto \\
\hline 2.4.2.10 & fundamento legal \\
\hline 2.4 .2 .11 & período de vigência \\
\hline 2.4 .2 .12 & valor do contrato \\
\hline 2.4 .2 .13 & situação do contrato (ativo, concluído, rescindido ou cancelado) \\
\hline 2.4 .2 .14 & $\begin{array}{l}\text { atalho para solicitar ao órgão ou entidade responsável, via correio eletrônico, a íntegra do } \\
\text { instrumento de contrato e respectivos aditivos }\end{array}$ \\
\hline 2.4 .2 .15 & $\begin{array}{l}\text { relação de aditivos ao contrato com as seguintes informações: número, data da publicação no } \\
\text { Diário Oficial, número do processo, objeto do aditivo }\end{array}$ \\
\hline 2.5 & Ações e Programas \\
\hline 2.5 .1 & lista dos programas e ações executados pelo órgão/entidade \\
\hline 2.5 .2 & indicação da unidade responsável pelo desenvolvimento e implementação \\
\hline 2.5 .3 & principais metas \\
\hline 2.5 .4 & indicadores de resultado e impacto, quando existentes \\
\hline 2.5 .5 & principais resultados \\
\hline
\end{tabular}

Quadro 2 - Informações mínimas da Seção de Acesso à Informação

Fonte: Legislação federal correlata

\begin{tabular}{|l|l|}
\hline \multicolumn{1}{|c|}{ Item } & \multicolumn{1}{|c|}{$\begin{array}{l}\text { Informação } \\
\text { Conteúdo Mínimo exigido pela Lei Complementar no 131/2009 e os normativos } \\
\text { relacionados a ela. }\end{array}$} \\
\hline 3.1 & Detalhamento das Despesas \\
\hline 3.1 .1 & Data da despesa \\
\hline 3.1 .2 & Valor do empenho, liquidação e pagamento \\
\hline 3.1 .3 & Número de processo da execução \\
\hline 3.1 .4 & Classificação orçamentária \\
\hline 3.1 .5 & Identificação da pessoa física ou jurídica beneficiária do pagamento \\
\hline 3.1 .6 & Procedimento licitatório realizado \\
\hline 3.1 .7 & Descrição do bem fornecido ou serviço prestado \\
\hline 3.1 .8 & Unidade gestora \\
\hline 3.2 & Detalhamento das Receitas \\
\hline 3.2 .1 & Data da posição \\
\hline 3.2 .2 & Unidade Gestora \\
\hline 3.2 .3 & Natureza da Receita \\
\hline 3.2 .4 & Valor da previsão \\
\hline 3.2 .5 & Valor do lançamento \\
\hline 3.2 .6 & Valor da arrecadação \\
\hline
\end{tabular}




\begin{tabular}{|c|c|}
\hline 3 & $\begin{array}{l}\text { Conteúdo Mínimo exigido pela Lei Compleão } \\
\text { relacionados a ela. }\end{array}$ \\
\hline 3.3 & Informações Financeiras (Art. 48 da LRF) \\
\hline 3.3 .1 & Plano Plurianual (PPA) \\
\hline 3.3 .2 & Lei de Diretrizes Orçamentárias (LDO) \\
\hline 3.3 .3 & Prestação de Contas \\
\hline 3.3 .4 & Relatório Resumido da Execução Orçamentária (RREO) \\
\hline 3.3 .5 & Relatório de Gestão Fiscal (RGF) \\
\hline 3.3 .6 & Balanço Anual do Exercício Anterior \\
\hline 3.4 & Procedimentos Licitatórios \\
\hline 3.4 .1 & $\begin{array}{l}\text { Informações concernentes a procedimentos licitatórios (Publicação que contenha todas as } \\
\text { informações relativas a procedimentos licitatórios, incluindo os respectivos editais e resultados, } \\
\text { bem como a todos os contratos celebrados, conforme Lei } 12.527 / 2011 \text { (Art. } 8^{\circ} \S 1^{\circ} \text { Inciso IV). }\end{array}$ \\
\hline 3.4 .2 & $\begin{array}{l}\text { Resumo dos instrumentos de contrato ou de seus aditivos e as comunicações ratificadas pela } \\
\text { autoridade superior, conforme Lei } 9.755 / 98 \text { (Art. } 1^{\circ} \text { inciso V); (Art. } 26 \text { caput); (Art. } 61 \S \\
\text { único); (Art. } 62 \S 3^{\circ} \text { ) e Lei } n^{\circ} 8.666 / 93 \text { (Arts. } 116,117,119 \text { e 124). }\end{array}$ \\
\hline 3.4 .3 & $\begin{array}{l}\text { Relações Mensais de todas as compras feitas pela Administração direta e indireta (Esta relação } \\
\text { deve discriminar, obrigatoriamente: identificação do bem comprado, seu preço unitário, a } \\
\text { quantidade adquirida, o nome do vendedor e o valor total da operação, podendo ser aglutinadas } \\
\text { por itens as compras feitas com dispensa e inexigibilidade de licitação, conforme Lei 9.755/98 } \\
\text { (Art. } 1^{\circ} \text { Inciso VI) e Lei 8.666/93 (Art. 16)). }\end{array}$ \\
\hline
\end{tabular}

Quadro 3 - Conteúdo mínimo exigido pela Lei Complementar nº 131/2009

Fonte: Lei Complementar no 131/2009 e legislação federal correlata

\section{Foram considerados os seguintes municípios como público-alvo do trabalho, conforme Tabela 1:}

Tabela 1- Municípios do Estado do Acre

IBGE

Municípios

Rio Branco

Cruzeiro do Sul

Sena Madureira

Tarauacá

Feijó

Marechal Thaumaturgo

Senador Guiomard

Mâncio Lima

Brasiléia

Rodrigues Alves

Plácido de Castro

Porto Acre

$\begin{array}{ll}\text { Código } & \text { Gentílico } \\ 1200401 & \text { rio-branquense } \\ 1200203 & \text { cruzeirense } \\ 1200500 & \text { sena-madureirense } \\ 1200609 & \text { tarauacaense } \\ 1200302 & \text { feijoense } \\ 1200351 & \text { thaumaturguense } \\ 1200450 & \text { guiomaense } \\ 1200336 & \text { mancio-limense } \\ 1200104 & \text { brasileense } \\ 1200427 & \text { rodriguesalvense } \\ 1200385 & \text { placidiano } \\ 1200807 & \text { portoacrense }\end{array}$

População 2010

Área da unidade

336.038

$8.835,54$

78.507

$8.779,39$

38.029

$23.751,47$

35.590

$20.171,05$

32.412

$27.974,89$

14.227

$8.191,69$

20.179

$2.321,45$

15.206

$5.453,07$

21.398

$3.916,50$

14.389

$3.076,95$

17.209

$1.943,25$

14.880

$2.604,86$ 


\section{A NOVA ORDEM DA INFORMAÇÃO E O ESTADO DO ACRE}

$\begin{array}{lrrr}\text { Acrelândia } & 1200013 \text { acrelandense } & 12.538 & 1.807,92 \\ \text { Epitaciolândia } & 1200252 \text { epitaciolandense } & 15.100 & 1.654,77 \\ \text { Porto Walter } & 1200393 \text { portowaltense } & 9.176 & 6.443,83 \\ \text { Xapuri } & 1200708 \text { xapuriense } & 16.091 & 5.347,45 \\ \text { Jordão } & 1200328 \text { jordãoense } & 6.577 & 5.357,28 \\ \text { Santa Rosa do Purus } & 1200435 \text { santarosense } & 4.691 & 6.145,61 \\ \text { Manoel Urbano } & 1200344 \text { manoel-urbanense } & 7.981 & 10.634,46 \\ \text { Capixaba } & 1200179 \text { capixabense } & 8.798 & 1.702,58 \\ \text { Bujari } & 1200138 \text { bujariense } & 8.471 & 3.034,87 \\ \text { Assis Brasil } & 1200054 \text { assis-brasiliense } & 6.072 & 4.974,18 \\ & & & \end{array}$

Fonte: IBGE/2010

Essa unidade federativa vem movimentando grande volume de recursos, por meio de convênios, como indica a Tabela 2:

Tabela 2- Recursos de transferências voluntárias para o Estado do Acre

\begin{tabular}{|c|c|c|c|c|c|}
\hline Municípios & Convênios & $\begin{array}{c}\text { Total das Ações de } \\
\text { Benefício Direto ao } \\
\text { Cidadão }\end{array}$ & $\begin{array}{c}\text { Total das } \\
\text { Outras Ações }\end{array}$ & Total Geral & $\begin{array}{c}\% \\
\text { Total dos } \\
\text { Municípios }\end{array}$ \\
\hline Rio Branco & 2186 & $45.777 .196,00$ & $460.670 .889,88$ & $506.448 .085,88$ & $47,75 \%$ \\
\hline Cruzeiro do Sul & 311 & $26.060 .037,00$ & $69.147 .455,74$ & $95.207 .492,74$ & $8,98 \%$ \\
\hline Sena Madureira & 147 & $12.561 .706,00$ & $35.087 .309,36$ & $47.649 .015,36$ & $4,49 \%$ \\
\hline Tarauacá & 89 & $12.582 .176,00$ & $33.983 .621,42$ & $46.565 .797,42$ & $4,39 \%$ \\
\hline $\begin{array}{l}\text { Feijó } \\
\text { Marechal }\end{array}$ & 83 & $10.667 .700,00$ & $26.238 .704,32$ & $36.906 .404,32$ & $3,48 \%$ \\
\hline $\begin{array}{l}\text { Thaumaturgo } \\
\text { Senador }\end{array}$ & 107 & $5.840 .458,00$ & $24.630 .173,11$ & $30.470 .631,11$ & $2,87 \%$ \\
\hline Guiomard & 124 & $4.996 .730,00$ & $24.497 .229,44$ & $29.493 .959,44$ & $2,78 \%$ \\
\hline Mâncio Lima & 125 & $8.138 .369,00$ & $20.537 .049,54$ & $28.675 .418,54$ & $2,70 \%$ \\
\hline Brasiléia & 182 & $5.774 .764,00$ & $21.465 .561,55$ & $27.240 .325,55$ & $2,57 \%$ \\
\hline Rodrigues Alves & 86 & $5.476 .866,00$ & $18.380 .471,24$ & $23.857 .337,24$ & $2,25 \%$ \\
\hline Plácido de Castro & 121 & $3.402 .798,00$ & $18.835 .917,44$ & $22.238 .715,44$ & $2,10 \%$ \\
\hline Porto Acre & 115 & $5.102 .304,00$ & $14.023 .480,37$ & $19.125 .784,37$ & $1,80 \%$ \\
\hline Acrelândia & 131 & $3.286 .841,00$ & $14.436 .138,85$ & $17.722 .979,85$ & $1,67 \%$ \\
\hline Epitaciolândia & 119 & $2.762 .192,00$ & $14.307 .329,71$ & $17.069 .521,71$ & $1,61 \%$ \\
\hline Porto Walter & 84 & $3.750 .204,00$ & $12.562 .204,68$ & $16.312 .408,68$ & $1,54 \%$ \\
\hline Xapuri & 109 & $3.674 .476,00$ & $12.248 .543,51$ & $15.923 .019,51$ & $1,50 \%$ \\
\hline $\begin{array}{l}\text { Jordão } \\
\text { Santa Rosa do }\end{array}$ & 47 & $3.531 .378,00$ & $12.358 .222,79$ & $15.889 .600,79$ & $1,50 \%$ \\
\hline Purus & 59 & $2.259 .018,00$ & $11.709 .136,27$ & $13.968 .154,27$ & $1,32 \%$ \\
\hline Manoel Urbano & 68 & $3.792 .620,00$ & $9.963 .164,21$ & $13.755 .784,21$ & $1,30 \%$ \\
\hline Capixaba & 104 & $2.305 .448,00$ & $10.183 .980,72$ & $12.489 .428,72$ & $1,18 \%$ \\
\hline Bujari & 108 & $2.443 .522,00$ & $9.569 .934,28$ & $12.013 .456,28$ & $1,13 \%$ \\
\hline Assis Brasil & 81 & $2.775 .834,00$ & $8.846 .348,55$ & $11.622 .182,55$ & $1,10 \%$ \\
\hline
\end{tabular}

Fonte: Portal da Transparência do Governo Federal, 2013. 
Movimentando recursos da ordem de $\mathrm{R} \$ 1.060 .645 \cdot 503,98$ o Estado do Acre se obriga a informar à sociedade civil cada passo das suas escolhas de gestão, para que a sociedade possa fazer o controle de sua governança. Para averiguar o status de acesso à informação pública no Estado, visitamos rigorosamente todos os sítios dos poderes executivo e legislativo do Estado, incluindo o TCE e o MP, este como poder autônomo e aquele como órgão auxiliar do poder legislativo.

As principais fontes de informação para elaboração desse roteiro, além da legislação citada, foram as seguintes publicações do Programa Brasil Transparente, desenvolvido pela Controladoria Geral da União:

1. GUIA de implantação de Portal da Transparência: publicação da Controladoria-Geral da união que tem o objetivo de orientar os gestores estaduais/municipais sobre como cumprir a Lei Complementar $n^{\circ} 131 / 2009$ e os normativos relacionados a ela.

2. GUIA para criação da Seção de Acesso à Informação nos sítios eletrônicos dos Órgãos e Entidades Estaduais e Municipais: publicação da Controladoria-Geral da união que tem o objetivo de orientar os órgãos e entidades estaduais e municipais para a implementação de seção sobre a Lei de Acesso à Informação (Lei no 12.527 , de 18 de novembro de 2011), em seus respectivos sítios eletrônicos institucionais.

Nesse sentido, vale salientar que os itens do $2^{\circ}$ bloco consistem em um nível de detalhamento mínimo para que haja o adequado entendimento das informações, de forma que não há um arcabouço normativo que exija de forma expressa cada item do detalhamento citado. Muitos dos itens, inclusive, seguem o padrão adotado pelo Portal da Transparência do Governo Federal. Todavia, o mesmo não ocorre com os itens do $1^{\circ}$ e $3^{\circ}$ bloco, tendo em vista que existe legislação específica que exige expressamente cada item citado.

Todas as informações exigidas pela legislação de transparência ativa são importantes. Todavia, cabe enfatizar as principais informações que podem ser utilizadas para aprimorar o controle interno e externo exercido por quaisquer instâncias de poder, bem como para auxiliar em atividades de repressão e combate à corrupção. Primeiramente, cabe frisar a necessidade de todas as entidades adotarem o conceito de dados abertos e estruturados na divulgação de suas informações. Com isso, a sociedade pode 
efetuar o download de quaisquer dados que tiver interesse e efetuar todo tipo de análise, inclusive em programas específicos, tais como: evolução de despesas no tempo, percentual de execução, concentração de despesas em determinadas naturezas, concentração de despesas para determinados credores, dentre outros (lembrando, ainda, que a divulgação de dados em PDF não atende a essa exigência). Cite-se como exemplo a aplicação dos itens 1.6 - Possibilidade de acesso por outros sistemas (Possibilidade de download dos dados) e 1.9 - Possibilidade de gravação de relatório: um determinado site pode permitir a exportação do relatório dos empenhos emitidos no mês de março (item 1.9), mas não disponibilizar ferramenta que permite a exportação dos empenhos emitidos nos últimos três anos (item 1.6).

Além disso, é de extrema importância a adequação aos ditames da Lei Complementar $n^{\circ} 131 / 2009$, no tocante à divulgação em tempo real da execução orçamentária e financeira, com um nível de detalhamento adequado, incluindo data, valores, dados de processos licitatórios, identificação completa do credor (com CPF ou CNPJ), dentre outros. Das entidades ora avaliadas, poucas estão adequadas nesse aspecto. Poucas entidades divulgam informações completas acerca das licitações realizadas, tais como: lista de todos os contratos, licitações, dispensas e inexigibilidades, editais, atas de julgamentos, recursos interpostos, julgamentos de recursos, dentre outras.

Cabe ressaltar novamente a necessidade de disponibilizar à sociedade 0 acesso às informações registradas no Sistema de Acompanhamento da Gestão de Recursos da Sociedade (SAGRES), de responsabilidade do Tribunal de Contas do Estado do Acre.

\subsection{Resultado da análise}

Também é parte integrante dessa pesquisa uma planilha com a avaliação individual de cada entidade, o endereço eletrônico utilizado para as consultas e observações sobre alguns pontos. Para os entes federativos com menos de dez mil habitantes (Porto Walter, Capixaba, Bujari, Manoel Urbano, Jordão, Assis Brasil e Santa Rosa do Purus) foram considerados apenas os itens do $3^{\circ}$ bloco do roteiro de análise (execução orçamentária das prefeituras).

Registre-se que não foram encontrados endereços eletrônicos para divulgação de informações das seguintes prefeituras municipais: Epitaciolândia, Rodrigues Alves, Capixaba e Bujari. Também não foram encontrados 
endereços eletrônicos para divulgação de informações das seguintes câmaras municipais de vereadores: Cruzeiro do Sul, Brasiléia, Senador Guiomard, Plácido de Castro, Mâncio Lima, Epitaciolândia, Rodrigues Alves, Marechal Thaumaturgo, Acrelândia, Porto Walter, Capixaba, Bujari, Manoel, Urbano, Jordão, Assis Brasil e Santa Rosa do Purus.

De forma resumida, o resultado encontrado foi o seguinte, conforme Tabela 3 e Figura 1:

Tabela 3 - Resultado em âmbito Estadual

\begin{tabular}{|c|c|c|c|c|c|}
\hline Entidades & $\begin{array}{c}\text { Governo } \\
\text { do Es- } \\
\text { tado do } \\
\text { Acre }\end{array}$ & $\begin{array}{c}\text { Assembleia } \\
\text { Legislativa }\end{array}$ & $\begin{array}{c}\text { Tribunal } \\
\text { de Con- } \\
\text { tas }\end{array}$ & $\begin{array}{c}\text { Ministério } \\
\text { Público }\end{array}$ & $\begin{array}{c}\text { Tribunal } \\
\text { de Jus- } \\
\text { tiça }\end{array}$ \\
\hline $\begin{array}{c}\text { Itens não } \\
\text { atendidos }\end{array}$ & 36 & 59 & 42 & 22 & 30 \\
\hline $\begin{array}{c}\text { Percentual } \\
\text { de atendi- } \\
\text { mento }\end{array}$ & $61,29 \%$ & $36,56 \%$ & $54,84 \%$ & $76,34 \%$ & $67,74 \%$ \\
\hline
\end{tabular}

Fonte: Pesquisa realizada no período de 04 a 08/03/2014

\section{Percentual de atendimento}

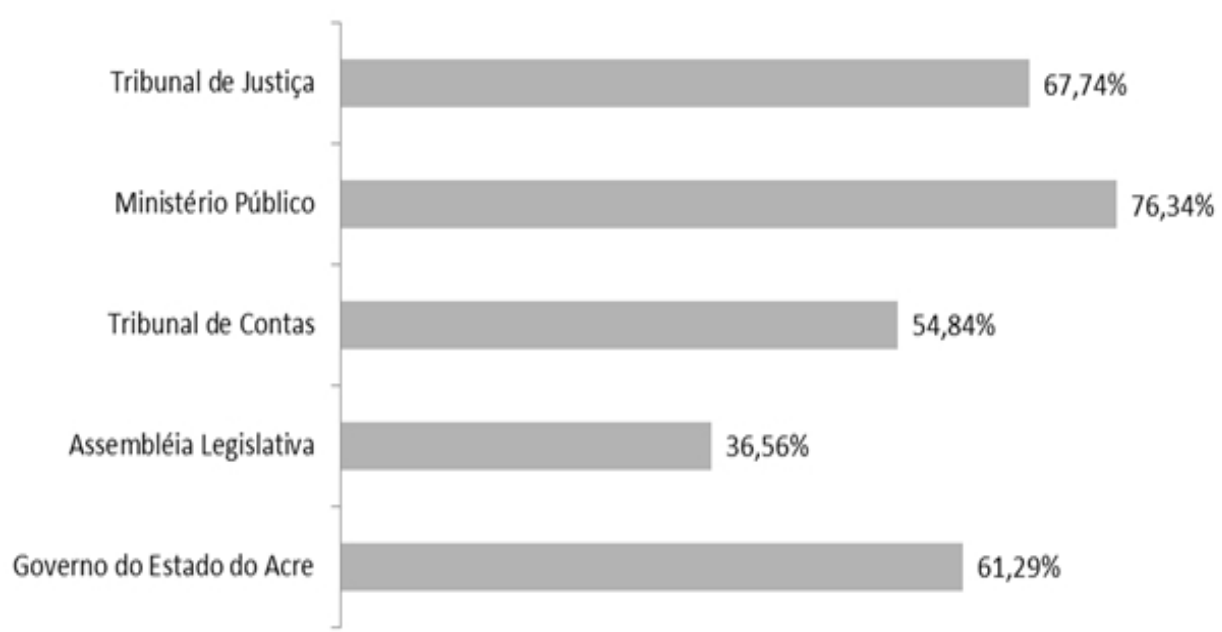

Figura 1 - Percentual de atendimento dos critérios normativos nos Poderes Fonte: Pesquisa realizada no período de 04 a 08/03/2014

Vê-se que os todos poderes estão em débito para com as exigência da nova ordem informativa, inaugurada pela Constituição e desenvolvida pela LAI. A Assembleia Legislativa e seu Tribunal de Contas possuem, respectivamente, índices de transparência de apenas $36,56 \%$ e 54,84\%. Ou seja, a ALE tem um déficit de transparência de $63,44 \%$ e o TCE de $45,16 \%$. O Poder Executivo apresenta um déficit de $38,71 \%$, o TJ de $32,36 \%$ e o MP de $23,66 \%$, 
sendo este o poder mais transparente, embora ainda com performance não satisfatória, como indicado na Tabela 4:

Tabela 4 - Medida de transparência negativa

\begin{tabular}{|l|l|}
\hline Poderes & Déficit de transparência \% \\
\hline ALE & 63,44 \\
\hline TCE & 45,16 \\
\hline P. EXEC & 38,71 \\
\hline TJ & 32,36 \\
\hline MP & 23,66 \\
\hline
\end{tabular}

Fonte: Pesquisa realizada no período de 04 a 08/03/2014

Por município, o déficit se torna mais explícito, como o demonstram a Tabela 5 e a Figura 2:

Tabela 5 - Medida de transparência no Poder Executivo Municipal

\begin{tabular}{|c|c|c|}
\hline Entidades & Itens não atendidos & \% de atendimento \\
\hline Rio Branco & 34 & 46,44 \\
\hline Cruzeiro do Sul & 50 & 29,03 \\
\hline Sena Madureira & 66 & 00,00 \\
\hline Tarauacá & 93 & 54,84 \\
\hline Feijó & 42 & 03,23 \\
\hline Brasileia & 90 & 39,78 \\
\hline Senador Guiomard & 56 & 38,71 \\
\hline Plácido de Castro & 57 & 22,58 \\
\hline Xapuri & 72 & 31,18 \\
\hline Mâncio Lima & 64 & 47,31 \\
\hline Porto Acre & 49 & 60,22 \\
\hline Marechal Thaumaturgo & 37 & 15,05 \\
\hline Acrelândia & 79 & 0,00 \\
\hline Porto Walter & 23 & 69,57 \\
\hline Manoel Urbano & 7 & 0,00 \\
\hline Jordão & 23 & 00,00 \\
\hline Assis Brasil & 23 & 04,35 \\
\hline Santa Rosa do Purus & 22 & \\
\hline
\end{tabular}

Fonte: Pesquisa realizada no período de 04 a 08/03/2014

Figura 2 - Percentual de atendimento dos critérios normativos no Poder Executivo Municipal 


\section{Percentual de atendimento}

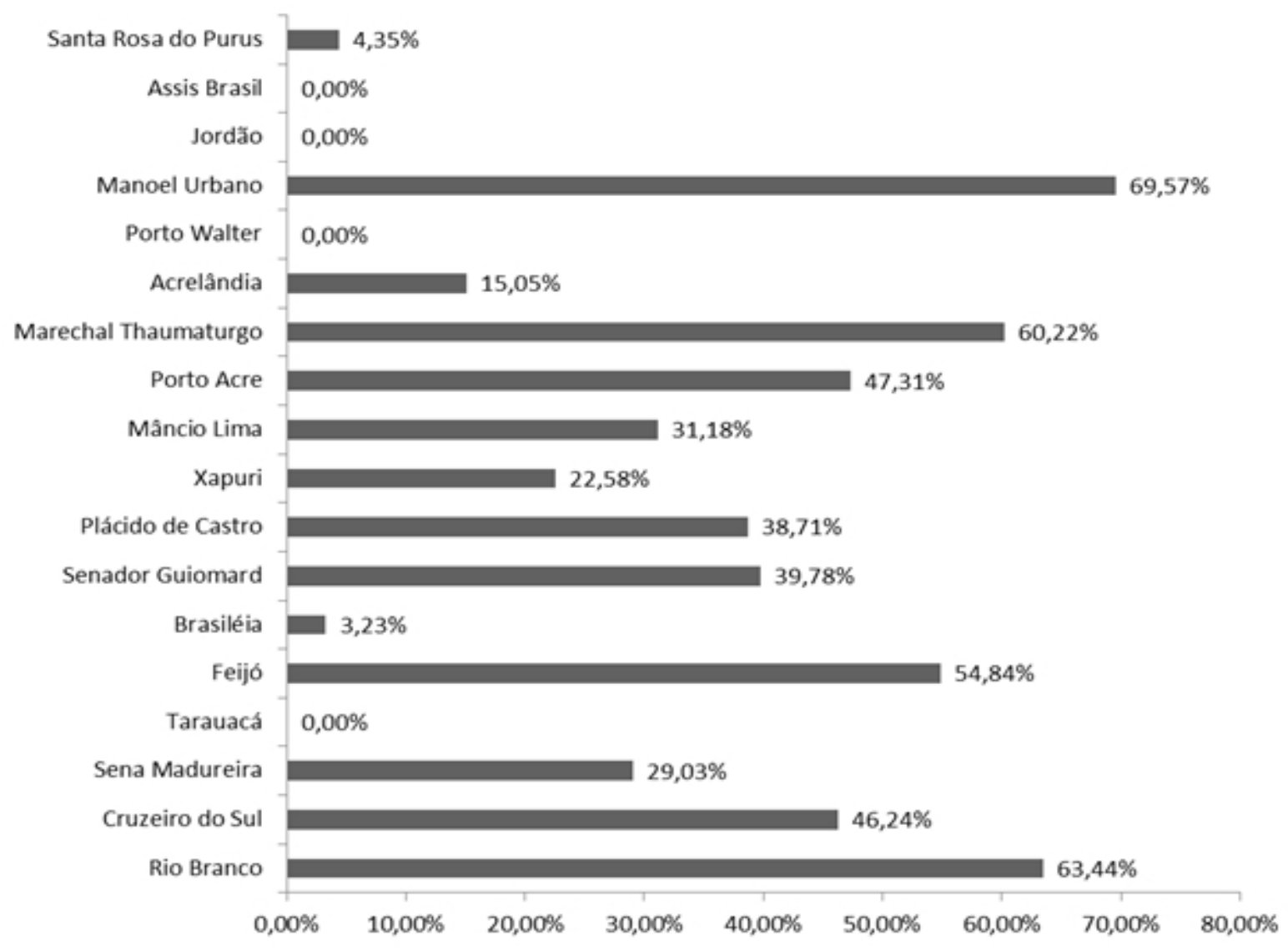

Fonte: Pesquisa realizada no período de 04 a 08/03/2014

No Poder Legislativo dessas unidades federativas, temos a seguinte situação, com baixíssimo índice de transparência, conforme Tabela 6 e Figura 3:

Tabela 6: Medida de transparência no Poder Legislativo Municipal

\begin{tabular}{|l|l|l|l|l|l|l|}
\hline \multicolumn{1}{|c|}{ Entidades } & Rio Branco & Sena Madureira & Tarauacá & Feijó & Xapuri & Porto Acre \\
\hline Itens não atendidos & 58 & 65 & 93 & 71 & 90 & 66 \\
\hline Percentual de atendimento & $37,63 \%$ & $30,11 \%$ & $0,00 \%$ & $23,66 \%$ & $3,23 \%$ & $29,03 \%$ \\
\hline
\end{tabular}

Fonte: Pesquisa realizada no período de 04 a 08/03/2014 
Figura 3 - Percentual de atendimento dos critérios normativos no Poder Legislativo Municipal

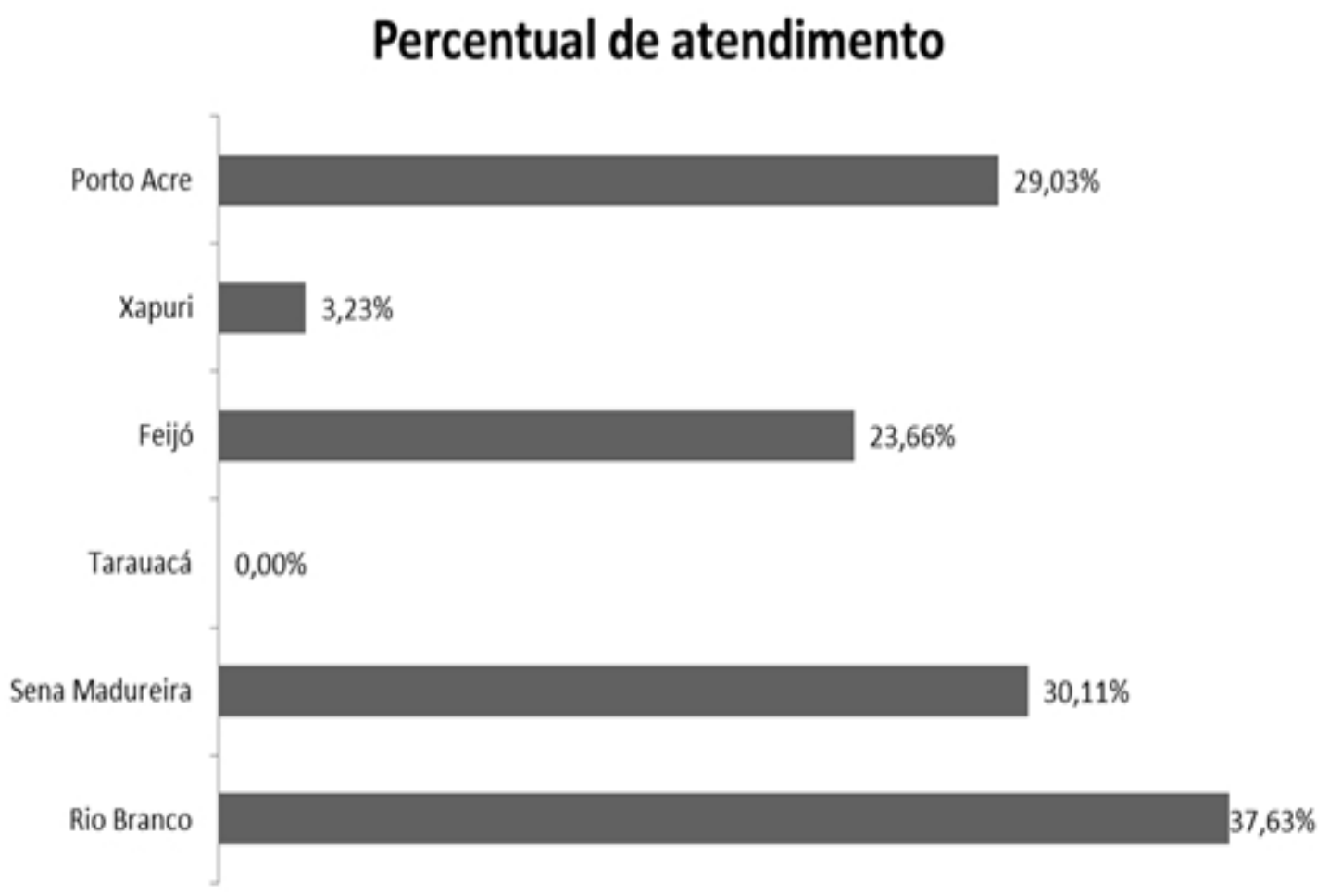

Fonte: Pesquisa realizada no período de 04 a 08/03/2014

\section{CONSIDERAÇÕES FINAIS}

O Estado do Acre ainda não franqueou o acesso às informações que dão conta de seu modus operandi à sociedade civil. Seu poder executivo e legislativo, incluindo o Tribunal de Conta do Estado e até o Ministério Público, estão muito aquém do nível de transparência exigido por nosso ordenamento jurídico. Em levantamento realizado em março de 2014, abrangendo todos os municípios dessa unidade federativa, verificamos que o Estado caminha a passos lentos para a nova ordem informativa.

Embora ao lado da LAl existam outros instrumentos constitucionais de controle de nossa democracia à disposição do cidadão, como o direito de petição ( $\operatorname{art.} 5 .^{\circ}$, XXXIV, "a"), o direito de certidão (art. 5. , XXXIV, "b") e o habeas data (art. 5., LXXII, "a" e "b"), o déficit de transparência infirma o que há de mais sagrado numa democracia, isto é, a assunção enfática do compromisso de se orientar pelo princípio republicano da publicidade, pilar da nova ordem da informação inaugurada por nossa Lei Maior e procedi- 
mentalizada pela Lei n 12527/11. Sem uma informação livre e íntegra o juízo público pode ser corrompido, afetando diretamente a liberdade de pensamento que não é senão a liberdade de apreender o mundo da vida com todos os seus problemas e contradições. Nesse viés, o direito fundamental à informação é conditio sine qua non para que a razão se desenvolva e a sociedade se aperfeiçoe no livre uso público do argumento, longe das sombras do autoritarismo.

\section{REFERÊNCIAS}

Constituição da República Federativa do Brasil., de 05 de outubro de 1988.

Lei $\mathrm{n}^{\circ} 12.527$, de 18 de novembro de 2011.

Lei Complementar n¹31/2009, de 27 de maio de 2009.

Lei Complementar $\mathrm{n}^{\circ}$ 101, de 4 de maio de 2000.

Lei $n^{\circ}$ 9.755, de 16 de dezembro de 1998.

Lei $\mathrm{n}^{\circ} 8.112$, de 11 de dezembro de 1990.

Lei $n^{\circ} 1.079$, de 10 de abril de 1950.

Decreto $n^{0} 7.724$, de 16 de maio de 2012.

Decreto $n^{\circ} 7.185$, de 27 de maio de 2010.

Decreto-Lei ${ }^{\circ}$ 201, de 27 de fevereiro de 1967.

http://dados.gov.br/dados-abertos

http://www.cgu.gov.br/PrevencaodaCorrupcao/BrasilTransparente/Servicos/MaterialTecnico.asp

CGU. Guia de implantação de Portal da Transparência. 2013. http://www.cgu.gov.br/Publicacoes/BrasilTransparente/Guia_PortalTransparencia.pdf

- Guia para criação da Seção de Acesso à Informação nos sítios eletrônicos dos Órgãos e Entidades Estaduais e Municipais. 2013. http://www.cgu.gov.br/Publicacoes/ BrasilTransparente/Guia_TransparenciaAtiva_EstadosMunicipios.pdf.

- Guia técnico de regulamentação da Lei de Acesso à Informação em Municípios e check list. 2013. http://www.cgu.gov.br/Publicacoes/BrasilTransparente/Guia_CheckList. pdf

. Manual da Lei de Acesso à Informação para Estados e Municípios. 2013.

Portal da Transparência do Governo Federal (http://ac.transparencia.gov.br/municipios) 
RECEBIDO EM: 09/09/2015

ACEITO PARA PUBLICAÇÃO: 01/08/2015

\section{Luis Satie}

Pós-doutor em Filosofia Política Normativa e Doutor em Filosofia e Ciências Sociais (EHESS - Paris), Mestre em Filosofia e Teoria do Direito (CPGD - UFSC) e Especialista em Ética e Filosofia Política (Departamento de Filosofia - UFSC). Pesquisador convidado do Grupo Neokantismo e Filosofia Contemporânea do CNPq/UFPB. E-mail: luis.satie@alumni-ehess.fr. Auditor Federal de Finanças e Controle na Controladoria-Geral da União.

\section{Ciro Jonatas de Souza Oliveira}

Graduado em Direito pela Universidade Federal do Acre, Especialista em Direito Público pela Universidade Anhanguera - Uniderp e Mestrando em Administração pela Universidade Federal da Bahia.E-mail: cirojonatas@gmail.com. Auditor Federal de Finanças e Controle na Controladoria-Geral da União. 
